\title{
Correction to: Ecological risk assessment of metals in sediments and selective plants of Uchalli Wetland Complex (UWC)—a Ramsar site
}

\author{
Sumera Gull Bhatti ${ }^{1} \cdot$ Amtul Bari Tabinda ${ }^{1} \cdot$ Faisal Yasin $^{2} \cdot$ Adeel Mehmood $^{3}$ - Muhammad Salman ${ }^{4} \cdot$ Abdullah Yasar $^{1}$. \\ Rizwan Rasheed $^{1} \cdot$ Rabia Wajahat $^{1}$
}

Published online: 25 May 2019

(C) Springer-Verlag GmbH Germany, part of Springer Nature 2019

\section{Correction to: Environmental Science and Pollution Research} https://doi.org/10.1007/s11356-019-04711-3

The correct image of Fig. 4 is shown in this paper.

The original article has been corrected.

The online version of the original article can be found at https://doi.org/ 10.1007/s11356-019-04711-3

Sumera Gull Bhatti

gul.environment@gmail.com

Amtul Bari Tabinda

amtulbaritabinda@gcu.edu.pk

Faisal Yasin

faisal.yasin@math.uol.edu.pk

Adeel Mehmood

adilqua5@gmail.com

Muhammad Salman

salman.chem@pu.edu.pk

Abdullah Yasar

yasar.abdullah@gmail.com
Rizwan Rasheed

riz_mian@hotmail.com

Rabia Wajahat

rabiyawajahat@yahoo.com

1 Sustainable Development Study Centre, Government College University, Lahore, Pakistan

2 Department of Mathematics and Statistics, The University of Lahore, Lahore, Pakistan

3 Government College Women University, Sialkot, Pakistan

4 Institute of Chemistry, University of the Punjab, Lahore, Pakistan 
Fig. 4 Scree plot of heavy metals in sediments. The graph shown in upper right corner shows the concentration of principle components variables in a loading plot

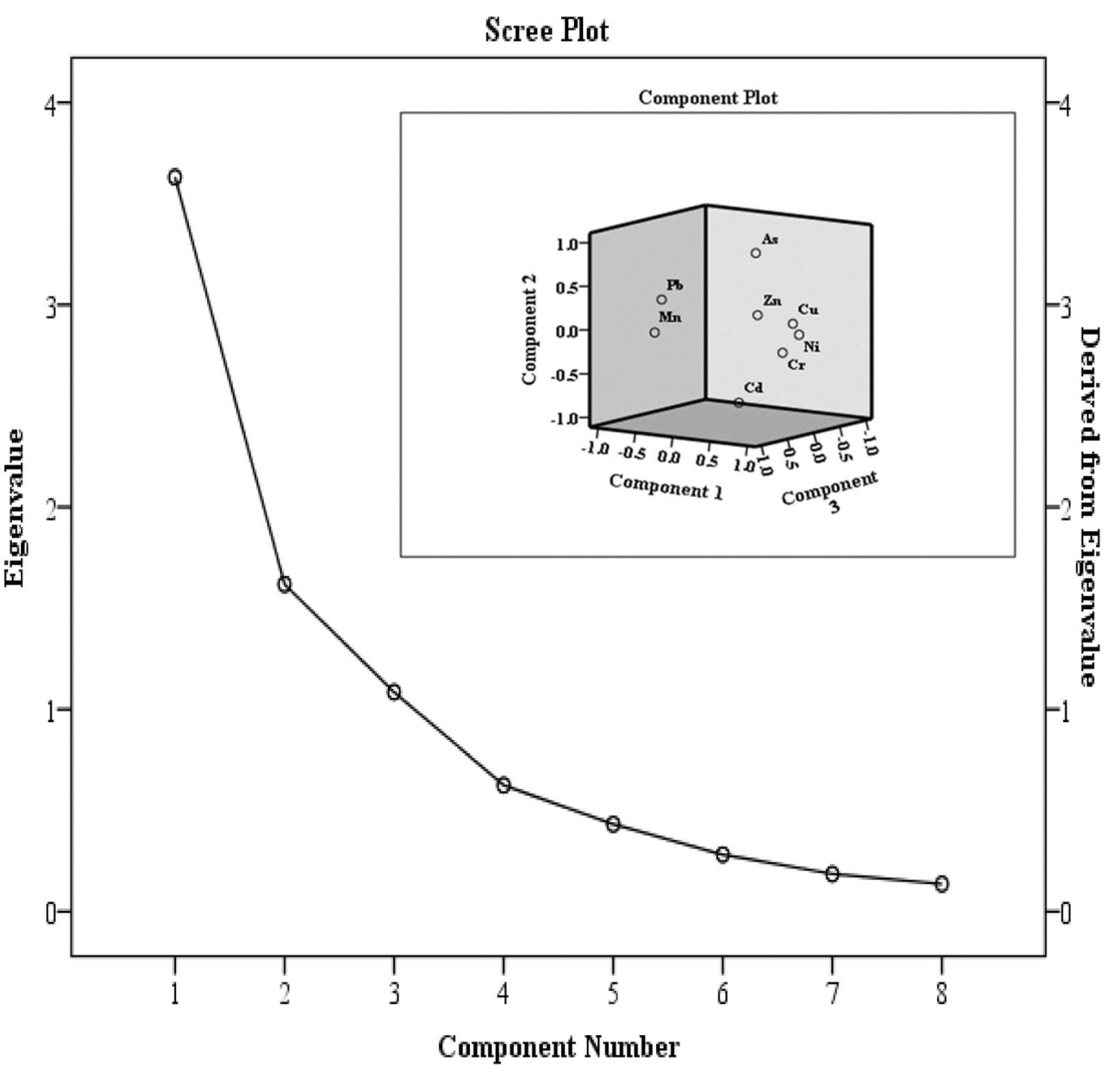

Publisher's note Springer Nature remains neutral with regard to jurisdictional claims in published maps and institutional affiliations. 